\title{
Psychological determinants of professional and personal medical students' growth: resources and development risks
}

\author{
Tatyana Shcherbakova ${ }^{1 *}$, Tatyana Loboda ${ }^{2}$ and Dinamutdin Misirov $^{3}$ \\ ${ }^{1}$ Rostov Institute of advanced training and professional retraining of education workers, 344041 \\ Rostov-on-Don, Russia \\ ${ }^{2}$ Rostov State Medical University, 344065 Rostov-on-Don, Russia \\ ${ }^{3}$ Southern Federal University, 344065 Rostov-on-Don, Russia
}

\begin{abstract}
The paper shows the main vectors of development of professional success of medical specialists in the context of modernization of modern medical practice. Based on the results of the analysis of modern requirements in the doctor as a subject of professional activity, psychological markers of its success are allocated. The article analyzes professionally significant personal qualities that act as internal determinants of successful professional activity of a modern doctor: moral, sociopsychological, emotional-volitional, as well as characteristics that act as markers of subjectivity formation: moral qualities, socio-psychological qualities, emotional-volitional qualities that allow to form and develop a competent style of professional behavior. The role of self - knowledge, reflection and professional self-consciousness of medical students in the effectiveness of their professional and personal growth and development of competence is shown. Based on the analysis of the results of empirical research, the article describes the content features of the views of modern medical students regarding the determinants of professional success, resources and risks of their development, shows the features of the severity of a number of psychological characteristics of modern medical students. The conceptual scheme of formation of psychological determinants of professional and personal growth of medical students is presented.
\end{abstract}

In the system of professional training of medical personnel today focuses not only on the need for the formation of professional competence, but also the development of personal resources, increasing personal maturity, responsibility and relevant profession values and meanings. Analysis of the results of psychological research allows us to identify and describe clusters of professionally significant personal qualities that act as internal determinants of successful professional activity of the modern doctor: moral, socio-psychological, emotional and volitional, as well as characteristics that act as markers of subjectivity.

\footnotetext{
*Corresponding author: tatiananik@1ist.ru
} 
Moral qualities set the moral and ethical system of coordinates in which the activity of the doctor and during the period of study at the University this point should be given special attention. According to psychologists, this block of qualities may include the following: integrity, honesty, unselfishness, humanity, responsibility, trust in yourself, others and the world, self-esteem, sense of duty, spirituality, benevolence.

At the same time, the doctor's activity takes place in an interactive space, as a rule, longterm interaction with the patient, which presents special requirements for its communicative resources and the level of formation of socio-psychological qualities that ensure the productivity and positivity of interactions. In this context, there are attraction, congruence, sociability and contact, attentiveness, tolerance, openness, empathy, interest, the ability to build supportive relationships.

An important role in the success of the professional activity of the doctor is the severity of the cluster of emotional and volitional qualities, such as commitment, perseverance, consistency, determination, demands, emotional stability, confidence. This cluster of qualities allows you to maintain a competent style of professional behavior in all circumstances and emergencies. The medical profession belongs to the class of risky, and the success of professional activity is directly correlated with the level of development of subjectivity of the doctor, which implies the presence of formed subjective control, clarity of life and professional position, courage and the ability to risk, autonomy and independence, independence, the ability to make decisions adequately reflecting the context of the implementation of activities, the ability to self-initialization, transformation and personal growth.

In modern sociorealism increases the proportion of socio-psychological factors that determine the success of the professional activity of the doctor, as in the information environment of knowledge about the possible means of treatment of the disease become available, and in the system of communication "doctor - patient" the productivity of cooperation and the choice of the route of medical care is largely determined by the ability of the doctor to become a reference subject.

Today, the professional success of the subject of the medical profession is considered as stating a high level of competence, effectiveness, productivity of communication, openness to innovation, willingness to take the initiative, the desire for constant self-improvement and self-realization, the ability to implement an individual concept of work and the degree of satisfaction of their own activity.

In the works of psychologists devoted to the study of professional success - the doctor as the determining factors are the following:

- cognitive, combining features of medical thinking, medical competence, development of the necessary qualities of attention, the ability to Gestalt information in accordance with the actual task, a high level of analytical activity;

- personal, including optimism, stability, enthusiasm, perseverance, the ability to influence others, expressed subjectivity;

- emotional, including stress resistance, expressiveness, emotional stability, the ability to control the representation of emotions;

- motivational, combining professional meanings and tsen6nosti, humanistic aspirations, motivation for success, the desire to achieve perfection;

- communicative, including readiness for intensive communication and cooperation, positivity, ability of active listening, ability to convince and argue, sociability.

In the space of interaction "doctor - patient" empathy plays an important role as a factor in increasing the productivity of communication in order to maximize the effectiveness of treatment. In the system of empathic abilities in V. A. Labunskaya's researches, [1] the following are allocated: to understanding and classification of emotional state of the partner, to presentation of emotional response, to shown patterns of behavior of another; congruence 
of cognitive, emotional and behavioral levels. Of great importance in the construction of effective communication "doctor - patient" has the character of a pragmatic attitude. From the point of view of O. I. Vorobyova [2], medical discourse has a number of functions in establishing productive cooperation with patients: from attracting attention to the problem of determining the position of both the disease itself and the process of its treatment. Adequate, pragmatic attitudes allow us to work for the future, positively transforming the patient's ideas about possible ways to solve the problem by Studying the features of empathy of the doctor, M. Hoiat [3] and M. D. Mahoney [4] showed that the effectiveness of interaction with patients is greatly influenced by the demonstration of interest, understanding the position of the patient, the manifestation of compassion and a detailed presentation of the desire to help and make progress in treatment. An important component of the professional success of specialists in the field of medicine is the adequacy of the image of the profession and the correct understanding of the resources and risks of both individual and professional in General.

In the works of S. N. Nakvasina [5], it is shown that medical students and residents often have idealized ideas about their profession and overestimated self-esteem, which complicates future adaptation and hinders success.

For the professional success of the doctor, the ability to decentralize, overcome egocentrism and centralization on the thoughts, potential experiences of the patient, modeling instructive changes in the emotional sphere and the experiences of the other is important. Stereotyping of professional behavior, its excessive formalization, is to some extent associated with an insufficient level of empathy, which makes it difficult to create the necessary psychological tone of communication in the "doctor - patient" system. In the studies of A. I. Kipiani [6] and E. V. Roshchevskaya [7] convincingly proved that a high level of empathy, as a significant component of the communicative resource of the doctor, directly correlates with the long-term forecast of professional success and satisfaction with the progress of the professional task.

In the conditions of modern resources and risks of implementation of professional activity in the field of medicine requires not only documentary, but also practical confirmation of professionalism. At the same time, building professional competence takes place in the context of continuous education and self-education, which, in fact, provides professional and personal growth, the effectiveness of self-improvement and creative activity. Self-knowledge is an important factor of successful professional development. At the same time in psychology stands out self-knowledge of their own meanings, values, aspirations, motives in all their diversity and ambiguity. This contributes to the axiological self-determination of the subject. An important role is also played by the level of development of professional selfawareness, awareness of their individuality, projected into the space of being in the profession, there is an awareness of the inconsistency of different images of the Self, which is an impulse to build their own line of professional life.

From the point of view of A. A. Rean [8], the optimal hierarchized complex of motives correlates with the degree of satisfaction with the profession. One of the risks is that according to the research of psychologists, doctors demonstrate conservatism in terms of selfdevelopment and personal transformations, while the professional situation requires the opposite. At the level of self-esteem, they tend to appreciate their personality and their ability to manage their emotional States and the behavior of others. On the one hand, it can be estimated as a resource, as to provide effective care to the patient, the doctor must be confident in himself and his abilities, but on the other - their reassessment can become a professional risk.

According to I. N. Denisov and M. V. Kholopov [9], modern reforms in the field of health care entail a change in the requirements for the medical education system, emphasizing the need for its modernization in the direction of significantly improving the quality of training, 
with an emphasis on the relevance of the content of acquired competencies and optimal use of resources. The innovativeness of modern medical practice, high technological effectiveness of medical activity today creates the need for the development of innovative, creative thinking of the doctor.

At the level of medical school, these components of the doctor's professionalism are developed by immersion in innovative research, design, simulation, professional modeling, which works on the formation of skills of non-standard associative thinking. The problem of satisfaction of the doctor as the subject of professional activity is interconnected with development of professional consciousness. From the point of view of subject-activity and resource approaches in a number of determinants of professional success and development of self-consciousness of the doctor, it is possible to allocate the focus on result, stability of motivation, emotional satisfaction and desire to continue to improve this activity and soya opportunities as its subject. In the context of the resource approach, satisfaction and high internal professional motivation are considered as significant personal resources to achieve efficiency. Self-initiation and self-determination in the professional activity of the doctor has a special meaning, since it is associated with a high emotional and intellectual direction and involves the ability of the subject to act in these conditions autonomously and productively.

Satisfaction with professional activity is considered as an integral unity of emotional positive and positive cognitive assessment of the course, result and overall psychological well-being.

The research of psychologists shows that the degree of psychological well-being affects the activity of the subject of medical work, the level of cooperation, the choice of constructive coping strategies and creativity in solving professional problems. The research of I. V. Abakumova emphasizes that satisfaction with professional activity in the field of anthropocentric professions is also influenced by the General index of life satisfaction, life values and attitudes, personal meaning [10].

In psychology, there are a number of indicators of satisfaction: expressed interest in the profession and life in General, high motivation for self-development, activity; commitment, passion, perseverance in achieving professional goals; consistency of desired goals and real achievements; positive, adequate self-assessment of professional activity and professionally significant qualities; constructive emotional background. In the process of predicting the success of teaching medical students, from the point of view of ad Donika [11], of great importance is the expression of value-semantic determining factors, to which psychologists include: education, erudition, independence, independence, responsibility, honesty, cheerfulness, good breeding. Students with high levels of total meaningfulness of life demonstrate faith in themselves and the future in the future, realize individual goals in life, internalnet, satisfaction with the current situation of life. The values of professional selfdetermination and personal life are declared as the preferred values, which is close to the characteristics of the self-actualizing personality. Students with low indicators of meaningfulness of life have more pronounced instrumental values, which can act as a risk of professional development and a barrier to achieving the essential success of the activity.

During the implementation of the empirical study, participants of which were medical students were identified and systematized their ideas about the psychological determinants of professional and personal growth. As such, students distinguish such as: the desire for success and recognition, the desire to improve the quality of life, self-esteem and the desire for self-realization, competition with others, the desire to be a useful specialist, the opportunity to learn a high status and material well-being, interest in the learning process at the University, the values of the professional team, the pleasure of self-presentation, the opportunity to receive financial encouragement, understanding of the mission of the doctor, the installation of self-improvement, competition in the student and professional environment, the availability of appropriate abilities, support from others, the presence of an 
example, different requirements. The following positions are reflected in the content of ideas and resources of development: high motivation, professional abilities, having a goal in the future, ambitions, traditions and atmosphere in the family, the ability to overcome obstacles, the thirst for victory, interest in what is happening, the desire to be competent. As potential risk factors are identified: reluctance, lack of abilities, self-confidence, majeure, resistance to requirements, lack of time, low interest in learning.

To build a conceptual scheme for the formation of psychological determinants of professional and personal growth of medical students, it is important to understand the features of their psychological portrait. In the course of the study it was found that modern medical students expressed the motivation of achievements, a high level of General internality and, at the same time, low rates of internality in the field of professional activity, interpersonal relationships and health, with respect to coping strategy preference is selfcontrol, planning solutions, avoidance and search for social support ,in the system of meaning-life orientations, high rates have the parameters of the purpose of life, the locus of control of life and the process of life, In terms of self-attitude, such positions as selfconfidence, self-guidance, self-worth and self-acceptance are distinguished as the most pronounced.

Thus, the data obtained are quite contradictory and suggest the need for appropriate work on the development of individual resources base of professional and personal growth of medical students. In the content of the conceptual scheme of organization of such work it is advisable to include the following blocks: installation-motivational, diagnostic-reflective, developing-training, effective-design.

\section{References}

1. V. A. Labunskaya, Psychological journal. 24, 14-22 (2003)

2. S. V. Vorobyov, Formation and development of intellectual abilities of medical College students (Place of defense: Moscow state University for the Humanities, Moscow, 2014)

3. M. Hojat J. S., Gonnella, T. J. Nasca, The American Journal of psychology, 1563-1569 (2002)

4. M. J Mahoney, The Scientific Foundation of Psychotherapy. (Basic Books, New York, 1991)

5. S. N. Nakvasina, Modern scientific research: methodology, theory, practice. (Center of assistance to development of scientific research, Krasnoyarsk, 2015)

6. A. I. Kipian, Development of communicative competence of a dentist as a condition of professional success (Stavropol state technical University, Stavropol, 2006)

7. E. V. Roshchevskaya, Russian psychological journal. 10, 44-54 (2013)

8. A. A. Rean, Psychology of personality adaptation. Analysis. Theory. Practice (PrimeEUROZNAK, St. Petersburg, 2006)

9. I. N. Denisov, Distance course "Fundamentals of distance learning technologies in higher medical education" (Moscow, 2007)

10. I. V. Abakumova, Smilodectes: the textbook for masters of pedagogics and psychology (CREDO, Moscow, 2008)

11. A. D. Donika, Medico-sociological analysis of the formation of professionally significant qualities of medical students (Printerr Design, Volgograd, 2005) 